\title{
A figuração da resistência: quatro jovens mulheres artistas em diálogo com o feminismo
}

Henrique Marques Samyn*

RESUMO: Trata-se de investigar o trabalho de quatro jovens mulheres artistas que atualmente vivem no Rio de Janeiro - Bárbara Gondar, Morgana Mastrianni, Juliana Gama e Mariana Paraízo "Mazô" -, considerando o contexto de reafirmação do feminismo no Brasil. No artigo, apresento uma síntese de suas trajetórias e comento algumas de suas produções artísticas, buscando compreendê-las como efeito da constituição de novas práticas coletivas inspiradas pelo feminismo; desse modo, pretendo oferecer elementos para a compreensão de um contexto que vem possibilitando a emergência de jovens mulheres que, através da produção artística, vêm criando uma resistência contra estruturas patriarcais ainda persistentes na sociedade brasileira.

PALAVRAS-CHAVE: feminismo, artes visuais, coletividade

ABSTRACT: We aim to investigate the work of four young women artists currently living in Rio de Janeiro - Barbara Gondar, Morgana Mastrianni, Juliana Gama and Mariana Paraizo "Mazo" -, considering the context of reaffirmation of feminism in Brazil. The article presents a summary of their trajectories and analyses some artistic productions, seeking to understand them as an effect of the constitution of new collective practices inspired by feminism; thereby, we intend to provide elements for the understanding of a context that has allowed the emergence of young women who, through artistic production, have created a resistance against persisting patriarchal structures in Brazilian society.

KEYWORDS: feminism, visual arts, collectivity

\footnotetext{
*Henrique Marques Samyn é Professor Adjunto no Instituto de Letras da Universidade do Estado do Rio de Janeiro, onde desenvolve projeto de pesquisa sobre modos de representação literários e pictóricos de sujeitos generificados, desde uma perspectiva diacrônica e transcultural, à luz da crítica feminista. Doutor em Literatura Comparada, tendo concluído Pós-Doutorado sobre a poética romântica, é ainda bacharel em Letras; bacharel em Filosofia; mestre em Psicologia Social; e mestre em Filosofia Moderna e Contemporânea.
} 


\section{Do momento}

Considerando os acontecimentos que alcançaram maior repercussão junto ao movimento feminista brasileiro em 2014, a ativista e escritora Jarid Arraes observou que, nesse período, o espaço concedido ao feminismo pela grande mídia nem sempre gerou resultados positivos, uma vez que o material veiculado pela imprensa muitas vezes reproduziu "valores machistas e estigmas impostos às mulheres"; por outro lado, consoante a articulista, a internet se revelou uma "ferramenta extremamente relevante para a militância das mulheres", de modo que "a militância feminista online foi capaz de conquistar mudanças concretas no país" (Arraes, 2014).

Com efeito, é fácil atestar o modo como a internet vem favorecendo a divulgação do ideário feminista: sobretudo desde a segunda década do século XXI, vêm-se multiplicando sites e blogs que vocalizam demandas e organizam manifestações em favor de mulheres vítimas das mais diversas formas de opressão - por sua expressão e/ou identidade de gênero, orientação afetiva e/ou sexual, origem étnica, condição físico-corporal ou posição social'. A militância feminista na internet também abrange a formação de grupos em redes sociais que se desdobram em coletivos que se reúnem fisicamente, com os mais diversos fins - desde encontros visando à realização de debates acerca da condição das mulheres até grupos acadêmicos e intervenções políticas; ademais, diversas entidades de orientação feminista vêm utilizando a internet para divulgar atividades e realizar campanhas políticas, tendo no entanto décadas de existência².

Essas circunstâncias têm difundido o feminismo junto a uma jovem geração que, de várias formas, vem assumindo explicitamente posições políticas em favor da emancipação das muIheres; por outro lado, a diversidade de manifestações atuais do feminismo brasileiro inclui expressões que dialogam com linguagens artísticas. Neste artigo, proponho uma análise em torno do impacto de questionamentos feministas nas criações de quatro artistas brasileiras Bárbara Gondar, Juliana Gama, Morgana Mastrianni e Mazô (Mariana Paraízo) -, atuantes no Rio de Janeiro, relativamente conhecidas em espaços feministas e em um circuito alternativo regional, que se situam em um estágio inicial no que tange à construção das carreiras, estudaram ou estudam em instituições reconhecidas e desenvolvem projetos estéticos consistentes. Assim, faculta-se o estabelecimento de um recorte para o exame de práticas artísticas contemporâneas nas quais a esfera coletiva desempenha um papel fundamental, sobretudo 
por intermédio de um constante diálogo com o feminismo - seja pelo contato com artistas e/ ou militantes, seja como interesse compartilhado que se concretiza na organização de eventos e exposições.

\section{Do contexto}

Constituindo um dos coletivos feministas de maior impacto no cenário global, as Guerrilla Girls - que se apresentam como "um grupo de mulheres anônimas que adota os nomes de artistas mulheres falecidas como pseudônimos e aparece em público vestindo máscaras de gorila" 3 - atuam desde 1985, utilizando elementos como pôsteres, adesivos e peças publicitárias. Empregando epítetos como "consciência da cultura" ou "consciência do mundo artístico", assumidos como pretensiosos e provocadores, e lançando mão do humor para disseminar informações e dados estatísticos que comprovam a exclusão das mulheres das esferas de produção cultural e artística, as Guerrilla Girls podem fornecer uma valiosa via para a abordagem da relação entre feminismo e arte na contemporaneidade.

Cabe destacar que, enquanto movimento emancipatório protagonizado por mulheres que lutam pela conquista e ampliação de seus direitos políticos, o feminismo desde sempre questionou as estruturas históricas que concorrem para sustentar a opressão com base nas distinções de gênero - para o que diversas vertentes feministas, desde os anos 1970, passaram a utilizar o conceito de patriarcado ${ }^{4}$. Operando de múltiplas formas na tessitura social, os dispositivos patriarcais propiciam o cerceamento da participação das mulheres não apenas no que tange às esferas política e econômica, mas também no que diz respeito à esfera cultural que com aquelas se relaciona; assim, o impedimento à presença feminina nos espaços de produção artística não tardou a estabelecer-se como ponto de interesse fulcral para teóricas e militantes. Devido às limitações de espaço, apresentarei apenas algumas anotações em torno das relações entre o feminismo e a arte contemporânea, precisamente a partir de um dos famosos cartazes produzidos pelas Guerrilla Girls. A obra, que chegou a receber uma doação de mil dólares oferecida por uma mulher para que fosse publicado em uma das principais revistas de arte estadunidenses, traz o texto que assim pode ser traduzido: 


\section{THE ADVANTAGES OF BENITG A WOMAN ARTIST: \\ Working without the pressure of success Not having to be in shows with men \\ Having an escape from the art world in your 4 free-lance jobs \\ Knowing your career might pick up affer you're eighty \\ Being reassured that whatever kind of art you make it will be labeled feminine \\ Not being stuck in a tenured teaching position \\ Seeing your ideas live on in the work of others \\ Having the opportunity to choose between career and motherhood \\ Not having to choke on those big cigars or paint in Italian suits \\ Having more time to work when your mate dumps you for someone younger \\ Being included in revised versions of art history \\ Not having to undergo the embarrassment of being called a genius \\ Getting your picture in the art magazines wearing a gorilla suit

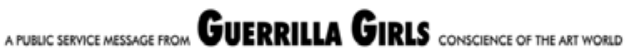

Guerrilla Girls

The Advantages of being a Woman Artist [As vantagens de ser uma artista mulher]. Litografia offset, 43,2 ×56 cm. 1989.

\section{AS VANTAGENS DE SER UMA ARTISTA MULHER:}

Trabalhar sem pressão por sucesso

Não ter que participar de exposições com homens

Poder escapar do mundo artístico em seus 4 trabalhos freelance

Saber que sua carreira pode deslanchar antes que você chegue aos oitenta

Ter assegurado que, qualquer que seja o tipo de arte que você faz, ela será rotulada como feminina

Não ficar empacada em uma posição estável de ensino

Ver suas ideias ganharem vida no trabalho de outros

Ter a oportunidade de escolher entre a carreira e a maternidade

Não ter que se engasgar com aqueles grandes charutos ou pintar em ternos italianos

Ter mais tempo para trabalhar quando seu companheiro trocar você por alguém mais jovem

Ser incluída em versões revistas da história da arte

Não ter que se submeter ao embaraço de ser chamada de gênio

Ter sua imagem nas revistas de arte vestindo uma roupa de gorila 
As sentenças constituem uma denúncia dos dispositivos que concorrem para excluir as muIheres do mundo artístico, alertando para os efeitos dessa exclusão - ironicamente qualificados como "vantagens." Uma mulher artista não precisa lidar com a pressão por sucesso, uma vez que dificilmente encontrará reconhecimento: se isso acontecer, será provavelmente de forma tardia, ou esse reconhecimento permanecerá restrito a trabalhos revisionistas. Uma mulher artista encontra dificuldades para expor seu trabalho, já que museus e galerias são espaços hegemonicamente masculinos - dado que se articula com outra série de pôsteres das Guerrilla Girls, que denuncia a quantidade de artistas mulheres presentes no Metropolitan Museum de Nova lorque: menos de $5 \%$ em 1985, número ainda menor em recontagens realizadas em 2005 (3\%) e $2012(4 \%)^{5}$. Uma mulher artista tem sua produção submetida a critérios de avaliação sexistas, que comumente a reduzem a estereótipos em torno da ideia de "feminilidade", facilitando a espoliação de suas ideias - particularmente por homens, visto que a ordem patriarcal associa a condição masculina à universalidade. Tudo isso cria dificuldades para a carreira profissional das mulheres artistas, forçando-as a buscar outras formas de sustento e diminuindo o tempo disponível para a criação artística - o que se soma aos empecilhos enfrentados pelas mulheres como um todo no ambiente profissional e social: a pressão pela maternidade, sem que às mães sejam oferecidas as condições ideais para que mantenham a carreira profissional; e a pressão pela adequação a padrões de beleza, o que tem evidente impacto sobre a sua autoestima. De tudo isso decorrem outras "vantagens": uma mulher artista não precisa passar pelo constrangimento de receber uma alcunha como "gênio", já que raras poderão ultrapassar tantos obstáculos e alcançar algum destaque; não precisará ostentar os charutos e ternos reservados para figuras de prestígio; e, finalmente, poderá aparecer em revistas de arte ostentando roupas de gorila - ou seja: quando conseguir destaque não como artista, mas como ativista e militante, à maneira das próprias Guerrilla Girls.

É por conta de barreiras desse tipo, que obstam a consolidação de carreiras profissionais de mulheres artistas, que as intervenções e produções coletivas feministas têm importância crucial. Em sentido político, o feminismo pode facultar às artistas a percepção crítica do modo como mecanismos patriarcais operam para assegurar a permanência da hegemonia masculina no mundo artístico; ademais, pode permitir-lhes o reconhecimento de preconceitos que prejudicam a recepção de suas propostas estéticas, que acabam reduzidas à tipicidade do "feminino". Em decorrência disso, as associações entre mulheres artistas para troca de 
informações e compartilhamento de experiências, concretizando-se na realização de eventos e exposições que Ihes permitem alcançar visibilidade e socializar suas produções artísticas, viabilizam a construção de espaços de resistência à ordem patriarcal.

Vale ainda ressaltar que as Guerrilla Girls possuem uma agenda política e um método de atuação definidos - cujo sucesso pode ser atestado tanto pela eficácia com que logram realizar suas denúncias quanto pela inserção de suas criações em prestigiadas coleções públicas, entre as quais se podem citar as do Centro Pompidou (Paris), do MoMA (Nova lorque), do Museu Reina Sofia (Madrid) e da Tate Modern (Londres) -, mas isso não legitima que sejam alçadas à posição de um modelo, o que seria contraprodutivo para a compreensão da multiplicidade de dinâmicas coletivas entre artistas feministas; com efeito, o caso daquelas de cuja produção trata este artigo apresenta características diversas, ainda que também se trate da construção de um espaço de resistência contra as estruturas que invisibilizam e solapam a participação de mulheres nos âmbitos de produção artística.

\section{Das artistas}

A importância da arte feminista na atualidade é reconhecida por críticos como Holland Cotter, para quem constitui a arte formativa das últimas quatro décadas e fonte de significativa parte da chamada arte pós-moderna; por outro lado, isso está relacionado com a sua abrangência (Chadwick, 2012, p. 498-499): se aquele conceito designa as formas de expressão artística que emergem em articulação com os movimentos emancipatórios de mulheres na segunda metade do século $X X$, aplica-se a um conjunto de produções que tematizam a identidade, a sexualidade, a história e a política, assumindo simultaneamente a tarefa de denunciar e combater estruturas opressoras e abrindo-se à pluralidade de linguagens artísticas disponíveis na contemporaneidade. Por conseguinte, apenas considerando a amplitude intrínseca ao conceito de arte feminista, bem como sua inerente multiplicidade de expressões, será possível utilizá-lo de forma produtiva para investigar as criações de Bárbara Gondar, Juliana Gama, Morgana Mastrianni e Mazố.

O aspecto coletivo da produção dessas artistas se concretiza por sua relação com o feminismo, consolidada no momento coevo de afirmação desse ideário político. Trata-se de jovens mulheres que, por vias diversas, conheceram em algum momento o pensamento feminista - através do contato pessoal com militantes, caso de Bárbara; da mescla de leituras com 
experiências em sociedades mais igualitárias, caso de Morgana; da convivência familiar com mulheres cuja atitude concretizava posturas feministas, caso de Juliana; do contato com blogs e páginas na internet, caso de Mazô - e que se dispuseram a aprofundar essa relação por intermédio da construção de redes e dinâmicas que viabilizaram a produção de criações artísticas nas quais aquela influência é reconhecida.

Cabe observar que, por conta da complexidade em torno da definição de arte feminista, há particularidades no modo como cada artista encara esse conceito. A esse propósito, pode ser interessante fazer uma breve reflexão contrastando declarações de dois importantes nomes da arte contemporânea. Kimsooja, artista sul-coreana radicada em Nova lorque, tem recusado em entrevistas a qualificação de seu trabalho como feminista, embora manifeste apoio pelos movimentos por direitos das mulheres e contra a discriminação por gênero; por outro lado, ao afirmar que "o feminismo é parte da minha natureza como uma mulher artista", justifica as leituras que teóricas feministas vêm reiteradamente apresentado de sua produção ${ }^{7}$ - trata-se, por conseguinte, de entender que o trabalho artístico realizado por uma mulher cujas posições políticas se coadunem com as defendidas pelo feminismo inevitavelmente terá implicações feministas, ainda que não aborde imediatamente questionamentos associados à opressão de gênero. Por outro lado, a estadunidense Lorna Simpson reconhece o quanto as questões desenvolvidas em sua produção artística envolvendo raça e gênero são influenciadas pelo contato com o movimento feminista negro nos anos 1970, o que está profundamente relacionado à sua abordagem da construção de narrativas identitárias - sobretudo pelo recorrente recurso visual a mulheres negras, sendo ela mesma uma mulher negra - e pelos questionamentos em torno da construção de sentidos a partir da experiência pessoal ${ }^{8}$. Nesse caso, a dimensão feminista é percebida como intrínseca à obra devido à condição concreta da artista que a produziu, em meio a relações de poder nas quais aspectos como gênero e raça carregam sentidos basilares.

No que tange à abordagem dos trabalhos artísticos aqui apresentados, buscarei propor leituras que respeitem os modos particulares como cada uma das artistas enxerga a relação de suas produções com o feminismo; ressalte-se, contudo, que todas se identificam como mulheres feministas, revelando-se sensíveis ao modo como questões envolvendo raça, classe, expressão e identidade de gênero, orientação afetiva e/ou sexual acabam por estruturar relações de poder, mesmo em grupos feministas ${ }^{9}$. 
Questionamentos em torno da identidade e do corpo, desde uma perspectiva explicitamente feminista, vêm ocupando um lugar central na produção artística de Bárbara Gondar, cujo trabaIho dialoga intensamente com a linguagem publicitária - meio em que atua profissionalmente há cerca de uma década, tendo realizado estudos na Escola Panamericana de Artes e trabaIhado em São Paulo como Diretora de Arte antes de transferir-se para o Rio de Janeiro, onde ingressou na Escola de Artes Visuais do Parque Lage. Seu trabalho começou a aproximar-se do feminismo nesse período, pela criação de zines - caminho comum a muitas produtoras de arte e cultura em circuitos alternativos, inclusive feministas.

A profundidade com que Bárbara vivencia o feminismo se reflete, por um lado, em sua disposição para organizar encontros catalisadores de debates e eventos como a feira Piranha, na qual mulheres puderam expor e comercializar sua produção artística; por outro lado, sua consciência política se manifesta na abordagem de valores fundamentais do ideário feminista. Bárbara Gondar parece especialmente interessada em resgatar o momento crucial na experiência daquelas mulheres que, em um determinado momento de sua vida, percebem-se alvo de estruturas de opressão; aquele momento epifânico em que toda a rede de poderes que configura e subalterniza a vivência da feminilidade se revela como artificial e reversível - em outras palavras: o momento mesmo em que a mulher se descobre feminista, não em um sentido abstrato ou teórico, mas no sentido concreto de descobrir-se como um sujeito político que faz da própria vida uma forma de resistência.

Um de seus trabalhos utiliza a arte sequencial para figurar o instante em que ocorre aquela epifania, que sempre implica alguma forma de ruptura na estabilidade cotidiana: é o momento da abertura para novas possibilidades de existência, na medida em que a subjetividade alcança a compreensão de que a condição concreta imposta à mulher em uma sociedade patriarcal não oferece outra via para a libertação, que não a resistência às estruturas que determinam o subjugo. Dese modo, interromper o ato mecanicamente reproduzido e constitutivo da rotina naturalizada - figurado no gesto de pedalar - e acolher as consequências daquele momento de revelação implica, necessariamente, uma reconstrução da ordem cotidiana - porque já não será possível pedalar da mesma maneira. 


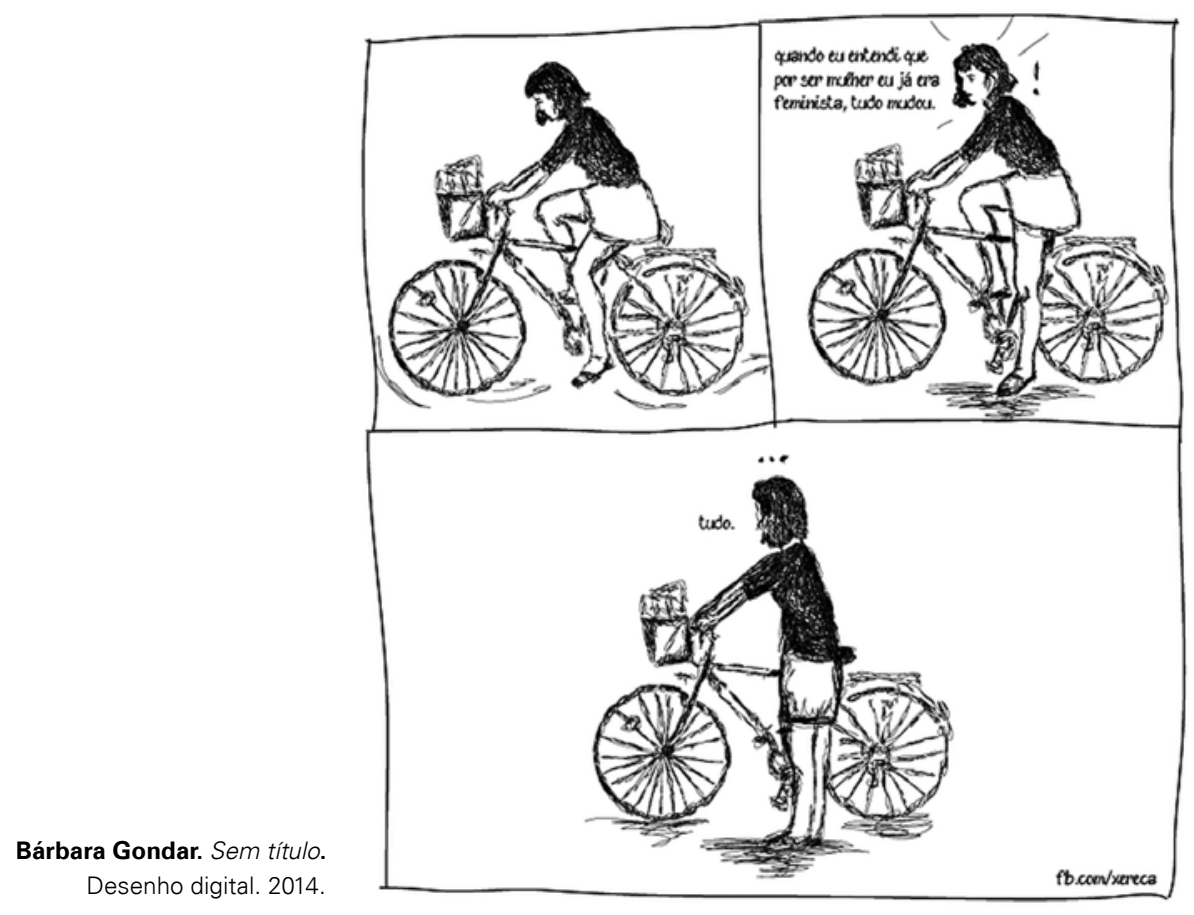

Com essa abordagem temática se articula a que transparece em outro trabalho de Bárbara Gondar, concebido como cartaz para a Marcha das Vadias de 2014. Para um evento contra a culpabilização de vítimas, a cultura do estupro e a estigmatização de sobreviventes de violência sexual ${ }^{10}$, Bárbara alude a uma questão basilar do feminismo: os processos de objetificação que espoliam as mulheres da agência sobre os seus próprios corpos, desumanizando-as. Construindo um contradiscurso à visão patriarcal que reduz a mulher ao exercício controlado de uma sexualidade que ela é supostamente incapaz de administrar, Bárbara recorre à exposição das entranhas como forma de aludir à condição essencialmente humana das mulheres, conquanto não deixe de figurar a vulva - que, na ordem binária, opera como marcador diferencial, sustentando a estrutura opressora. Trata-se, portanto, de resgatar o substrato humanista da luta política feminista, o que necessariamente envolve o reconhecimento da ordem patriarcal como algo que deve ser combatido. 


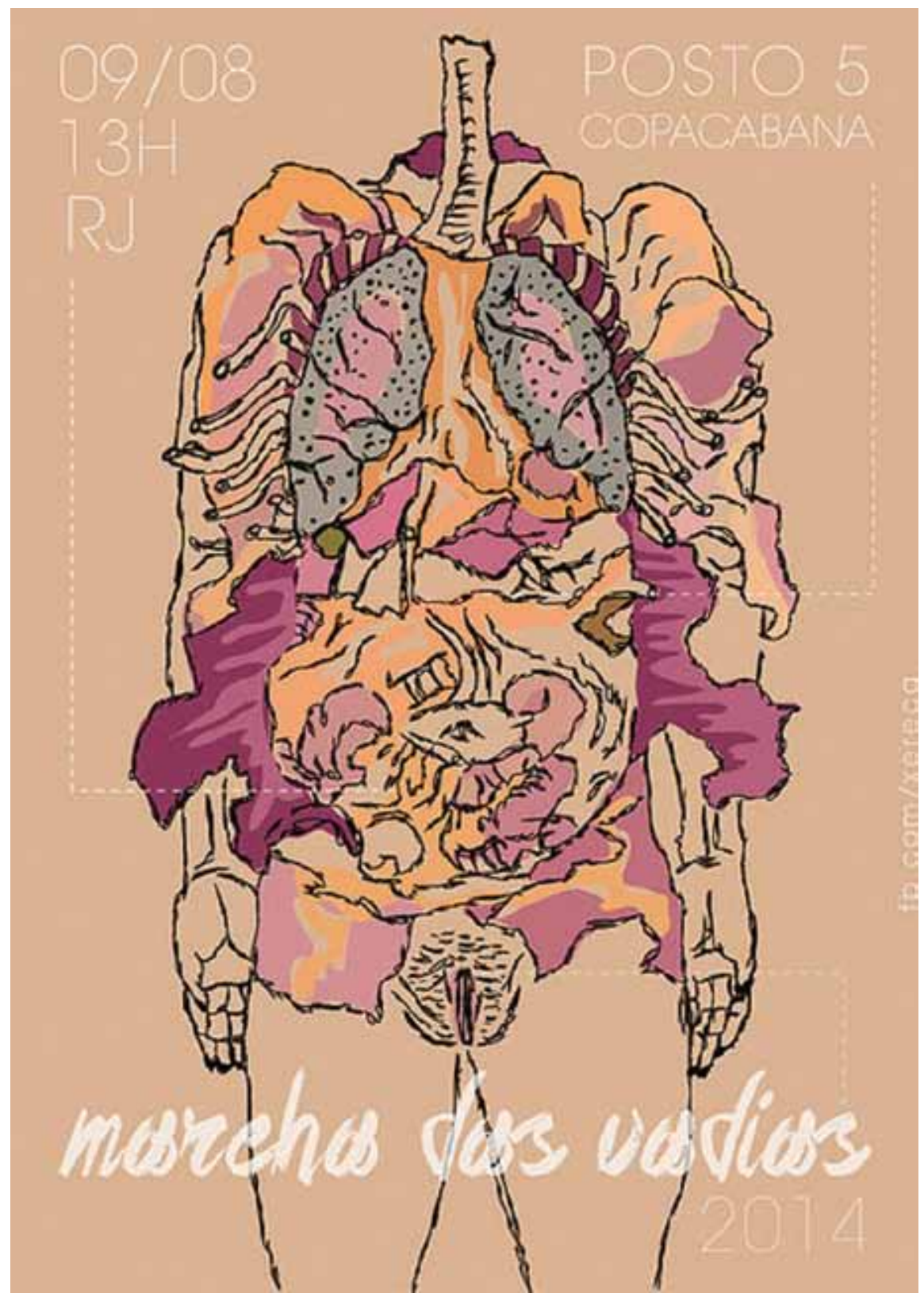

Bárbara Gondar. Sem título.

[cartaz para Marcha das Vadias]. Desenho digital. 2014. 
Temário distinto, mas não menos próximo do feminismo, é desenvolvido por Morgana Mastrianni. Tendo ingressado na Escola de Belas Artes da Universidade Federal do Rio de Janeiro (EBA-UFRJ) para estudar Indumentária, Morgana posteriormente percebeu que seus interesses poderiam ser melhor desenvolvidos no curso de Pintura, para o qual se transferiu; em 2013, aprofundou os estudos na Academia Real de Arte (KABK) da Holanda. Do contato com leituras feministas e da experiência na sociedade holandesa, notoriamente mais igualitária que a brasileira, resultou a progressiva incorporação de questões associadas ao feminismo em seu trabalho, que envolve a colaboração em diversos projetos coletivos organizados por artistas mulheres.

A produção de Morgana Mastrianni se desdobra na criação de pinturas e desenhos que constituem diferentes suportes para o desenvolvimento de um temário que vem explorando os processos de construção de narrativas pessoais. A referência a aspectos autobiográficos, não obstante, resgata dispositivos de opressão de gênero que ultrapassam os limites da experiência individual, sobretudo por estarem vinculados às dinâmicas de poder que atuam no espaço familiar ou que se sustentam em princípios e valores religiosos. Ciente de sua posição como mulher, artista e feminista, Morgana reconhece que produzir para si mesma, sobretudo no que tange ao seu trabalho como quadrinista - o que implica a atuação em um ambiente no qual a hegemonia masculina se revela particularmente opressora -, já constitui um ato de resistência.

Cura resulta de um trabalho concebido ainda na passagem pela Holanda, posteriormente publicado na produção coletiva Zine $X X X$, em que a arte sequencial é utilizada para tratar de uma condição de isolamento e um sentimento de culpa que acabam por induzir a um estado alucinatório de matizes mórbidos. A narrativa criada, consciente ou inconscientemente, para dar conta de uma situação-limite não se restringe, contudo, à especificidade; com efeito, Cura reflete a condição de incontáveis mulheres nas quais a ordem patriarcal impinge a noção de uma falta irremediável associada à emergência do desejo. O que há de mais cruel e eficaz na culpa, como dispositivo de poder patriarcal, é a capacidade de fazer das mulheres as primeiras agentes de sua própria aniquilação, na medida em que exige uma extinção da própria condição feminina de sujeito desejante; e é essa experiência extrema, ainda que cotidianamente vivenciada por muitas mulheres, o que Morgana tematiza neste trabalho. 

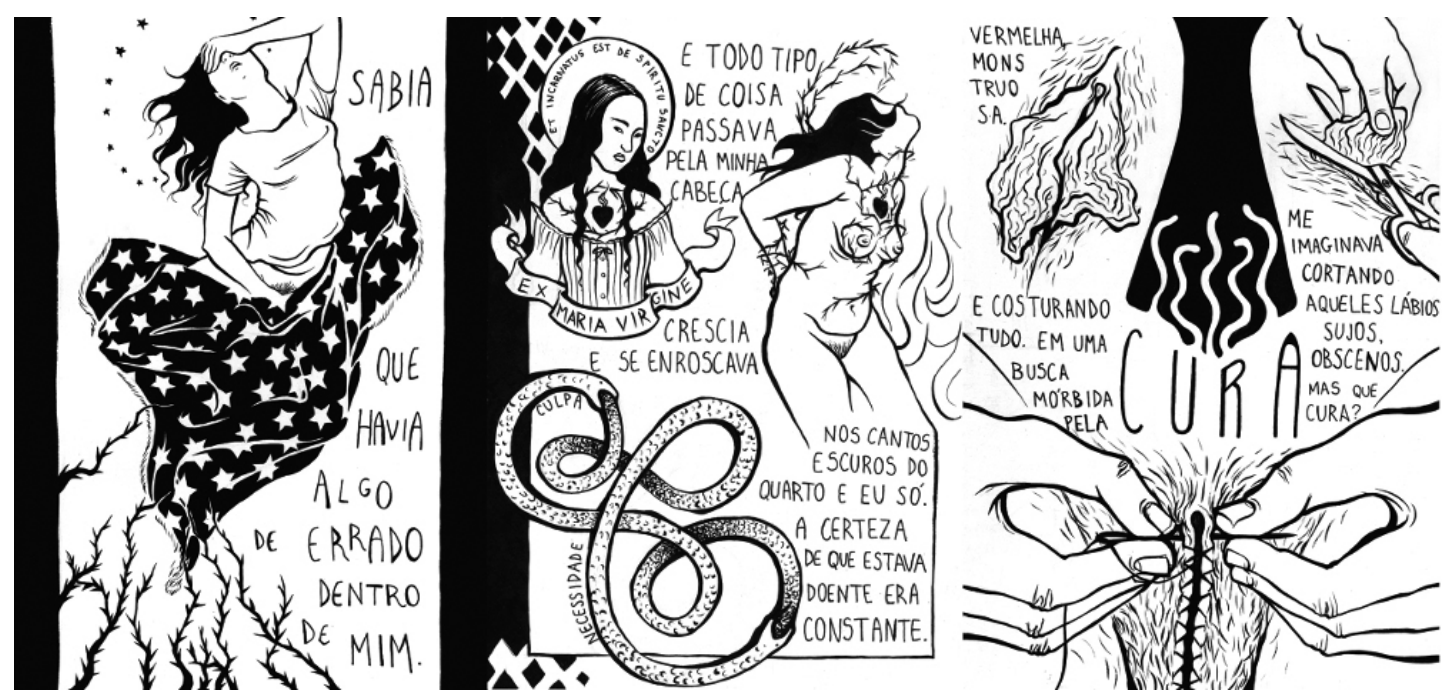

Morgana Mastrianni

Cura. nanquim sobre papel, 3 folhas de $21 \times 29,7 \mathrm{~cm} .2013$.

Em outra vertente de sua produção artística, Morgana Mastrianni vem trabalhando em uma série de retratos de familiares próximos, assim construindo um conjunto de pinturas no qual a representação de pormenores fisionômicos concorre para a composição de uma narrativa que viabilize a busca de uma consciência étnica - algo também motivado pela experiência na Holanda, quando aos grupos de brasileiros eram atribuídas, pelos europeus, as nacionalidades mais diversas. A criação dos retratos responde, por conseguinte ao questionamento acerca da construção de uma identidade multiétnica a partir das heranças familiares; desse modo, como já foi anteriormente ressaltado, pinturas e desenhos representam vertentes complementares de um mesmo questionamento, em torno da multiplicidade de elementos reconhecidos e articulados pela subjetividade para a construção de uma narrativa pessoal. 
artísticas que possibilitem questionar as múltiplas formas de opressão exercidas sobre as muIheres na ordem patriarcal. Em decorrência disso, seus trabalhos frequentemente mesclam diversas técnicas, não raro recorrendo ao uso de objetos cotidianos, para explorar um temário em que, recentemente, vêm se destacando questionamentos em torno do modo como a violência de gênero se materializa frequentemente sob a máscara de discursos que não apenas a dissimulam, mas a convertem em algo pretensamente benéfico e positivo para as mulheres.

Os dois trabalhos aqui reproduzidos constituem etapas de uma pesquisa em torno da medicalização como um dos mais poderosos dispositivos de opressão sobre as mulheres na contemporaneidade. Happy pills é uma colagem que mescla comprimidos e uma bula de antidepressivos ao contorno de uma figura humana que, à luz das convenções sociais, será lida como o retrato de uma mulher - cuja ambígua atitude, combinada à forte cor de fundo e ao título do trabalho, aludem à construção de uma imagem artificiosamente sexy e elegante. Juliana Gama assim denuncia como, sob discursos que supostamente visam ao bem-estar, ocultam-se mecanismos que moldam identidades, constroem rotinas e modos de vida, tendo as mulheres como alvo privilegiado. 


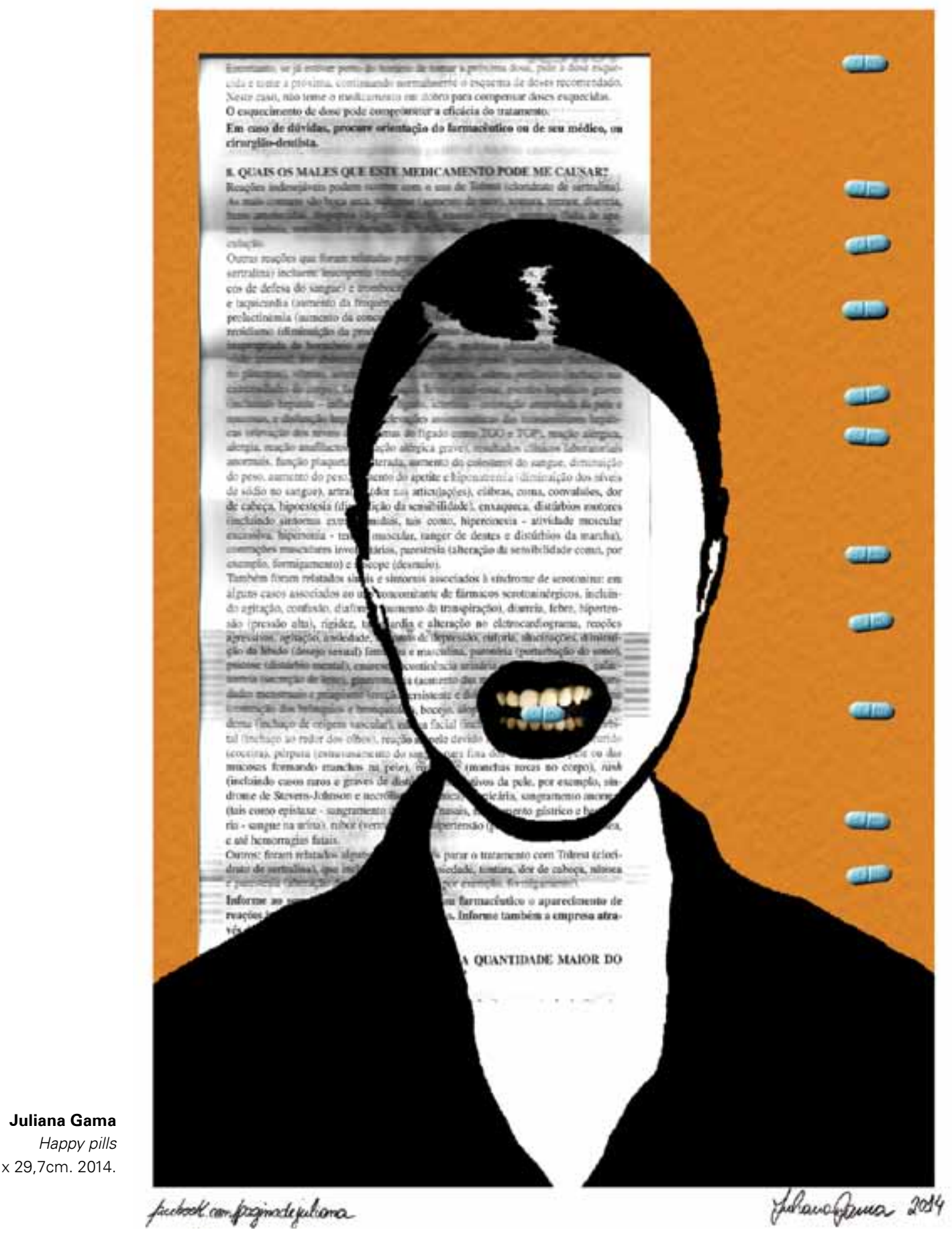


Uma segunda etapa dessa pesquisa questiona de que modo essas rotinas de medicalização, uma vez naturalizadas como meios de promover um melhor qualidade de vida, acabam por propiciar a construção de tipologias que servem a padrões de normalidade. Neste conjunto de trabalhos, Juliana Gama vem utilizando fotografias 3x4 suas e de mulheres com as quais mantém contato, vistas como de algum modo "inadequadas" pela sociedade patriarcal, sobre as quais intervém com imagens ou objetos que remetem ao uso de medicamentos. Trata-se, assim, de denunciar os procedimentos de patologização da vida cotidiana como dispositivos de poder que, na verdade, buscam disciplinar tudo aquilo que é percebido como divergente ou dissidente, promovendo um cerceamento das identidades tidas como indesejáveis.
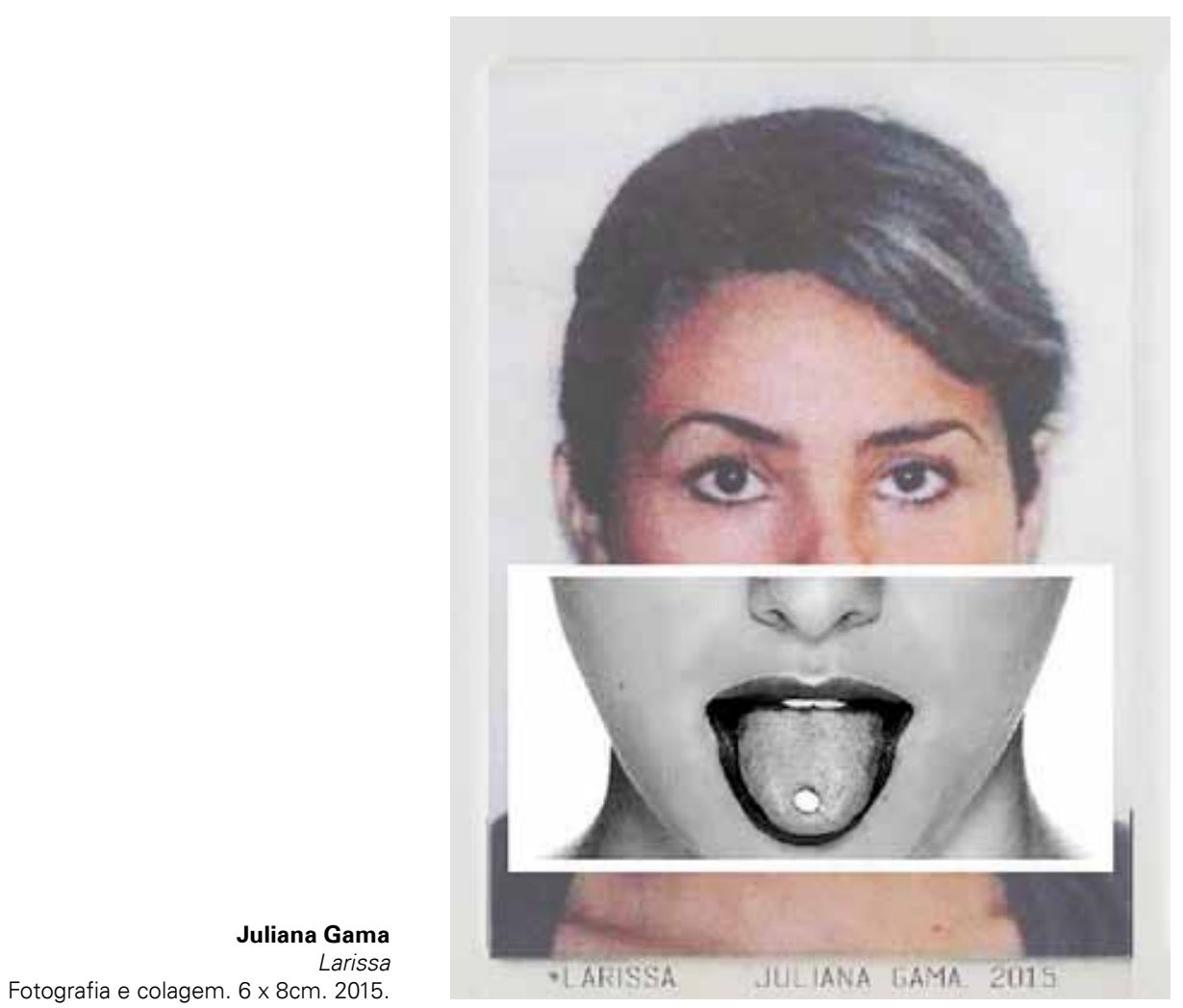
Finalmente, Mazô, a mais jovem entre as quatro artistas, cedo teve estimulado seu interesse pela arte - sobretudo pela mãe, professora de arte em escolas públicas. Tendo iniciado os estudos em cursos livres, em 2014 começou a cursar gravura na Escola de Belas Artes da UFRJ, ingressando também na Escola de Artes Visuais do Parque Lage. Participou do já mencionado Zine $X X X$, ao lado de outras jovens artistas; posteriormente, iniciou a elaboração de zines próprios e o desenvolvimento de diversos projetos artísticos.

$\mathrm{O}$ ativismo feminista realizado pela internet foi o que possibilitou a Mazô estabelecer um contato com o ideário político do movimento pela emancipação das mulheres, do que resultou a incorporação de questionamentos associados ao feminismo em seus trabalhos. A partir da percepção de que toda e qualquer produção artística encerra um posicionamento político - o que, na verdade, pode ser dito a respeito de qualquer produção humana -, entende Mazô que, sendo mulher e feminista, seu trabalho necessariamente refletirá um conjunto de crenças e valores pessoais que implicarão em questionamentos estéticos que tangenciam o feminismo, mesmo que não de maneira exclusiva. Suas últimas pesquisas vêm cada vez mais incorporando a crítica de práticas e discursos que legitimam exclusões a partir de critérios patriarcais, geográficos e capacitistas.

A série Viagem ao Centro da Terra, iniciada em 2013, utiliza recursos da arte sequencial para questionar os processos constitutivos da subjetividade desde uma perspectiva desterritorializante. Mazô maneja ludicamente um amplo repertório de elementos convencionais de forte sentido político - bandeiras nacionais, ou seja, signos intrinsecamente relacionados à produção de sujeitos no âmbito da modernidade - apenas para "dessacralizá-los", ou despojá-los de qualquer função solene, e construir narrativas voltadas a dilemas relacionados a seu próprio cotidiano. Nessa medida, a ideia de "centro da terra" remete à própria subjetividade que interpreta e ressignifica tudo aquilo que a cerca em favor da construção de uma ficção pessoal - o que, pela via inversa, também pode ser visto como uma problematização da dificuldade humana de lidar com a alteridade.

O mesmo processo de leitura do mundo a partir de circunstâncias concretas vem sendo tematizado em uma série de gravuras em metal em que Mazô mescla imagens fotográficas e textos escritos em braille. Nesse caso, importa perceber que a própria recepção do trabalho depende dos recursos disponíveis por quem está diante dele e está ou não apto a apreendê-lo 
no todo ou em parte; assim, questiona-se radicalmente qualquer pretensão à universalidade no que diz respeito à experiência artística, uma vez que essa depende não só de elementos como a formação, a educação ou valores pessoais, por exemplo, mas de circunstâncias particulares que variam individualmente.

\section{Da coletividade}

As produções artísticas de Bárbara Gondar, Morgana Mastrianni, Juliana Gama e Mazô são indissociáveis da posição que ocupam como jovens mulheres, artistas e feministas - não apenas porque seus trabalhos dialogam com essa orientação política, mas também porque suas condições de produção não podem ser plenamente compreendidas caso isso seja negligenciado. Por outro lado, quando indagadas por outras feministas com as quais mantêm contato ou que de algum modo influenciam os seus trabalhos, algumas das artistas mencionaram nomes como Evelyn Queiróz "Negahamburguer," Laura Lannes, Aline Lemos "Desalineada", Laura Athayde, Tailor, Gabriela Masson "Lovelove6" e Dayanna Lima, o que explicita a existência de um contexto no qual diversas jovens mulheres vêm dialogando e produzindo.

Quando se considera a força que estruturas patriarcais ainda mantêm no meio artístico global - particularmente no brasileiro -, evidencia-se em que medida as práticas coletivas sustentadas por jovens artistas, inspiradas pelo feminismo, viabilizam a formação de uma rede de resistência na qual mulheres podem articular-se, criar espaços próprios para exposição e comercialização de seus trabalhos e construir um público disposto à recepção de novas linguagens e formas de expressão artística, ensejando a emergência de cenários alternativos que, em alguns casos, chegam a oferecer possibilidades de atuação profissional, para além da viabilização de projetos através do financiamento coletivo.

Por conseguinte, se neste artigo abordei apenas o trabalho de quatro artistas entre as inúmeras que produzem contemporaneamente no Brasil, importa perceber que este recorte espelha um momento no qual o feminismo vem possibilitando o surgimento de uma nova geração de mulheres que vem encontrando meios para enfrentar mecanismos historicamente consolidados que, por longo tempo, impuseram obstáculos àquelas que desejavam dedicar-se à produção artística. Em outras palavras: a revolucionária tarefa feminista de combater as estruturas patriarcais vem sendo proficuamente realizada por essa nova geração de mulheres 
artistas, para as quais o ideal de construção de um mundo livre do sexismo vem produzindo mudanças concretas que já abrem novos e promissores horizontes.

Artigo recebido em maio de 2015, aprovado em junho de 2015 e publicado em julho de 2015.

\section{NOTAS}

1 Uma lista não-exaustiva que arrole apenas sites coletivos poderia mencionar, entre outros, os sites Blogueiras Feministas (atuante desde 2010), Ativismo de Sofá (atuante desde 2012), Blogueiras Negras (atuante desde 2013) e FemMaterna (atuante desde 2013).

2 A guisa de exemplo pode-se citar as ONGs CFEMEA - Centro Feminista de Estudos e Assessoria, fundada em 1989, e Católicas pelo Direito de Decidir, atuante no Brasil desde 1993, que mantêm páginas e perfis em redes sociais.

3 No original: "[...] a bunch of anonymous females who take the names of dead women artists as pseudonyms and appear in public wearing gorilla masks" (trad. minha). Cf. Guerrilla Girls Frequently Asked Questions. Note-se que o uso das máscaras tem por base os termos guerrilla/gorilla, homófonos-heterográficos na língua inglesa. Cf. Guerrilla Girls Bare All: an interview.

4 Ressignificação operada no âmbito da teoria feminista que subsume o conceito de origem sociológica para designar "a hegemonia masculina nas sociedades antigas e modernas" (Puleo, 1995, p. 21; trad. minha).

5 Sobre outros contextos, ver a resenha de Ana Paula Cavalcanti Simioni do catálogo Elles@centrepompidou. Artistes Femmes dans La Collection du Musée National d’Art Moderne, Centre de Création Industrielle (Simioni, 2011); e o artigo de Rebecca Corrêa e Silva e de Ursula Rosa da Silva sobre exposições museológicas recentes que, entre 2011 e 2012, expuseram exclusivamente obras de mulheres, realizadas no Museu de Arte do Rio Grande do Sul Ado Malagoli e no Museu Francisco Tavares Proença Júnior, de Castelo Branco, Portugal (Corrêa e Silva; Silva, 2014).

6 Nas análises, utilizei material proveniente de entrevistas realizadas com as artistas entre 14 e 23 de janeiro de 2015 , que forneceram elementos sobre suas trajetórias biográficas e profissionais.

7 Cf. a entrevista para o catálogo de exposição no Kunsthalle Wien: Matt, 2002; para interpretações feministas, cf. Chadwick, 2012, p. $485-486$.

8 Cf. a entrevista a Siri Engberg and Sarah Cook (Engberg; Cook, 1999). Para uma leitura feminista exemplar de uma das mais importantes obras de Simpson, cf. hooks, 1995.

9 Todas as artistas, nas entrevistas que com elas realizei, enfatizaram sua compreensão do feminismo como necessariamente intersecional

10 Cf. Slutwalk Toronto. Frequently Asked Questions.

\section{Referências}

ARRAES, Jarid. “Feminismo 2014: para não esquecer". Revista Fórum Semanal. n. 178, 19 dez. 2014. Disponível em: http://revistaforum.com.br/digital/178/feminismo-2014-para-nao-esquecer/. Acesso em: 15 janeiro 2015. 
CHADWICK, Whitney. Women, art, and society. $5^{\text {a }}$ ed. Londres: Thames \& Hudson, 2012.

CORRÊA E SILVA, Rebecca; SILVA, Ursula Rosa da. Memória e poder. mulheres artistas nas exposições museológicas no Brasil e em Portugal. Revista Confluências Culturais. Joinville. v. 3, n. 1. 2014.

ENGBERG, Siri; COOK, Sarah. Interview with Lorna Simpson: March 9, 1999. Disponível em: http://www.walkerart.org/archive/F/ B4737D1B1BCC13206169.htm. Acesso em: 20 janeiro 2015.

GUERRILLA GIRLS. Guerrilla Girls Frequently Asked Questions. Disponível em: http://www.guerrillagirls.com/interview/faq.shtml. Acesso em: 15 janeiro 2015.

. Guerrilla Girls Bare All: an interview. Disponível em: http://www.guerrillagirls.com/interview/index.shtml. Acesso em: 15 janeiro 2015

. The Advantages of being a Woman Artist. Disponível em: http://www.guerrillagirls.com/posters/advantages.shtml. Acesso em: 15 janeiro 2015

HOOKS, bell. Facing difference: the black female body. In: Art on my mind: visual politics. Nova lorque: New Press, 1995

MATT, Gerald. Interview with Kimsooja. 2002. Disponível em: http://www.kimsooja.com/texts/matt.html. Acesso em: 20 janeiro 2015 PULEO, Alicia. Patriarcado. In: AMORÓS, Celia. Diez palabras clave sobre mujer. 4a. ed. Estella: Verbo Divino, 1995.

SIMIONI, Ana Paula Cavalcanti. A difícil arte de expor mulheres artistas. Cadernos Pagu, Campinas, n. 36, Jun. 2011. Disponível em: http://dx.doi.org/10.1590/S0104-83332011000100014. Acesso em: 15 janeiro 2015.

SLUTWALK TORONTO. Frequently Asked Questions. Disponível em: www.slutwalktoronto.com/about/faqs . Acesso em: 20 janeiro 2015 . 